\title{
PENGARUH DIRECT DAN IN-DIRECT QUENCHING DENGAN MEDIA AIR TERHADAP KEKERASAN HASIL HARDFACING BAJA KARBON
}

\author{
Direct and In-Direct Water Quenching Effect to Hardness of Hardfacing Layers \\ on Carbon Steel
}

Ferry Budhi Susetyo*, Imam Basori dan Dwi Maryanto

Universitas Negeri Jakarta, Jl. Rawamangun Muka, Rawamangun, Jakarta Timur, Indonesia

Informasi artikel

Diterima: $28 / 04 / 2020$

Direvisi : 09/05/2020

Disetujui: 24/06/2020

\begin{abstract}
Abstrak
Penelitian ini bertujuan untuk mengetahui pengaruh direct-quenching dan furnace-quenching dengan media air terhadap nilai kekerasan dan struktur makro hasil hardfacing menggunakan elektroda HV 600. Proses direct quenching satu dilakukan hardfacing dua lapis dengan satu kali quenching menggunakan air, pada proses direct quenching dua dilakukan hardfacing dua lapis dengan dua kali quenching menggunakan air. Selanjutnya pada spesimen furnace quenching dilakukan proses hardfacing dua lapis, kemudian dilanjutkan proses heat treatment dengan variasi holding time (10, 20 dan 30 menit) lalu dilakukan quenching menggunakan air. Kekerasan furnace quenching lebih tinggi jika dibandingkan direct quenching. Pada spesimen furnace quenching semakin lama holding time dalam furnace maka nilai kekerasannya akan menurun. Penggunaan direct quenching sangat menjanjikan, karena dapat meningkatkan nilai kekerasan tanpa mengeluarkan biaya untuk pemanasan ulang dalam tungku (furnace heat treatment).
\end{abstract}

Kata Kunci: quenching, hardfacing, kekerasan, baja, HV 600.

\begin{abstract}
This study aims to determine the effect of direct-quenching and furnace-quenching with water media on the value of hardness and macro structure resulting from hardfacing using HV 600 electrodes. One direct quenching process is carried out by two layers of hardfacing with one quenching using water, while two direct quenching processes are carried out double layer hardfacing with two times quenching using water. Furthermore, the quenching furnace specimen is carried out a two-layer hardfacing process, then proceed with the heat treatment process with a variation of holding time (10, 20 and 30 minutes) then quenching using water. The hardness of furnace quenching is higher when compared to direct quenching. In the furnace quenching specimen the longer the holding time in the furnace, the hardness value will decrease. The use of direct quenching is very promising, because it can increase the value of violence without incurring the cost of reheating in the furnace.
\end{abstract}

Keywords: quenching, hardfacing, hardness, Steel, HV 600. 


\section{PENDAHULUAN}

Perkembangan teknologi dibidang konstruksi sekarang ini sangat maju, salah satunya adalah teknologi dibidang pengelasan. Pada umumnya las digunakan untuk menyambung dua material seperti material alumunium (Soebagyo et al., 2019). Selain untuk penyambungan, proses las juga dapat digunakan untuk untuk mempertebal permukaan material dengan tujuan memberikan lapisan yang lebih keras (Oo dan Muangjunburee, 2018). Hal-hal yang perlu diperhatikan ketika proses penebalan meliputi pemilihan elektroda, pemilihan mesin las, dan parameter pengelasan (Ahmed et al., 2015). Untuk menghasilkan kekerasan yang tinggi, penggunaan polaritas DC+ sangatlah menjanjikan untuk digunakan dalam proses penebalan permukaan material (Susetyo et al., 2019).

Dalam bidang pertanian maupun perkebunan saat ini banyak menggunakan excavator kecil dimana menggunakan material baja karbon rendah. Baja karbon sangat banyak digunakan, karena mudah dibentuk dan dari segi harga yang relatif murah (Susetyo, et al., 2020). Baja karbon memiliki sifat tidak bisa dikeraskan langsung melalui heat treatment tanpa melalui proses pengerasan permukaan (hardfacing). Penggunaan baja karbon seperti bucket traktor memerlukan kekerasan yang tinggi, karena jika digunakan secara terus menerus dan terjadi interaksi maka dalam jangka waktu tertentu akan menimbulkan keausan (Saini et al., 2016).

Begitu banyak metode yang digunakan untuk meningkatkan ketahanan keausan dari suatu benda kerja, salah satunya dengan hardfacing (Sopiyan et al., 2019). Hardfacing juga dapat meningkatkan kekerasan pada keausan pada benturan, temperatur tinggi, ketahanan korosi dan sebagainya (Singh, 2014). Selain metode hardfacing meningkatkan kekerasan pada baja karbon rendah dilakukannya pendinginan secara cepat (quenching) (Hafni 2015; Basori dan Syamsuir 2019). Pada saat didalam tungku waktu tahan (holding time) menjadi faktor pengaruh pada kekerasan hasil proses quenching (Sardi et al., 2018). Semakin lama holding time baja ASSAB 760 maka akan semakin tinggi nilai kekerasannya ketika dilakukan quenching dengan media oli (Bangsawan et al., 2012), namun ketika dilakukan dengan media coolant menjadi terbalik, yaitu semakin lama holding time maka akan semakin lunak (Utama et al.,
2016). Semakin lama waktu tahan (holding time) tentunya akan semakin menambah biaya produksi dari suatu material karena konsumsi listrik yang besar dari operasional furnace. Terdapat penelitian yang menggunakan waktu tahan (holding time) selama 10 menit (Basori dan Syamsuir, 2019)

Pada penelitian (Susetyo et al., 2020) yang mengemukakan pada Proses hardfaching 3 lapis menggunakan elektroda HV 600 pada baja karbon rendah dilakukan heat treatment temperatur $1000^{\circ} \mathrm{C}$ dengan variasi holding time 30 menit, 60 menit dan 90 menit, serta di quenching dengan media oli, menghasilkan nilai uji kekerasan tertinggi terdapat pada spesimen holding time 90 menit dengan nilai kekerasan 674,06 VHN dan nilai uji keras terendah terdapat pada spesimen holding time 30 menit menghasilkan nilai kekerasan 624,74 VHN.

Berdasarkan paparan diatas, perlu dilakukan penelitian tentang pengaruh direct quenching dan furnace quenching dengan media air terhadap nilai kekerasan hasil hardfacing menggunakan elektroda HV 600, untuk mengetahui perbandingan nilai kekerasan antara spesimen direct-quenching dan furnace-quenching.

\section{METODOLOGI}

\section{Waktu dan Tempat Penelitian}

Penelitian ini dilakukan pada bulan september sampai dengan Desember 2019, tempat yang digunakan adalah Laboratorium Produksi, las dan Material, Teknik Mesin Universitas Negeri Jakarta.

\section{Alur Penelitian}

Pada penelitian ini menggunakan istilah direct quenching dan furnace quenching. Direct quenching adalah proses quenching tanpa mengalami pemanasan didalam tungku atau dengan kata lain ketika spesimen selesai di las (masih berwarna merah) kemudian seketika itu langsung dicelupkan ke dalam media pendingin air. Furnace quenching adalah proses quenching dengan terlebih dahulu spesimen mengalami pemanasan dengan suhu dan waktu tertentu didalam tungku kemudian langsung dicelupkan ke dalam media pendingin air.

Penelitian diawali dengan proses harfacing, kemudian proses heat treatment lalu proses uji keras dan pengamatan struktur makro. Penjelasan mengenai prosedur penelitian dijelaskan dalam bentuk skema seperti terlihat pada gambar 1 . 


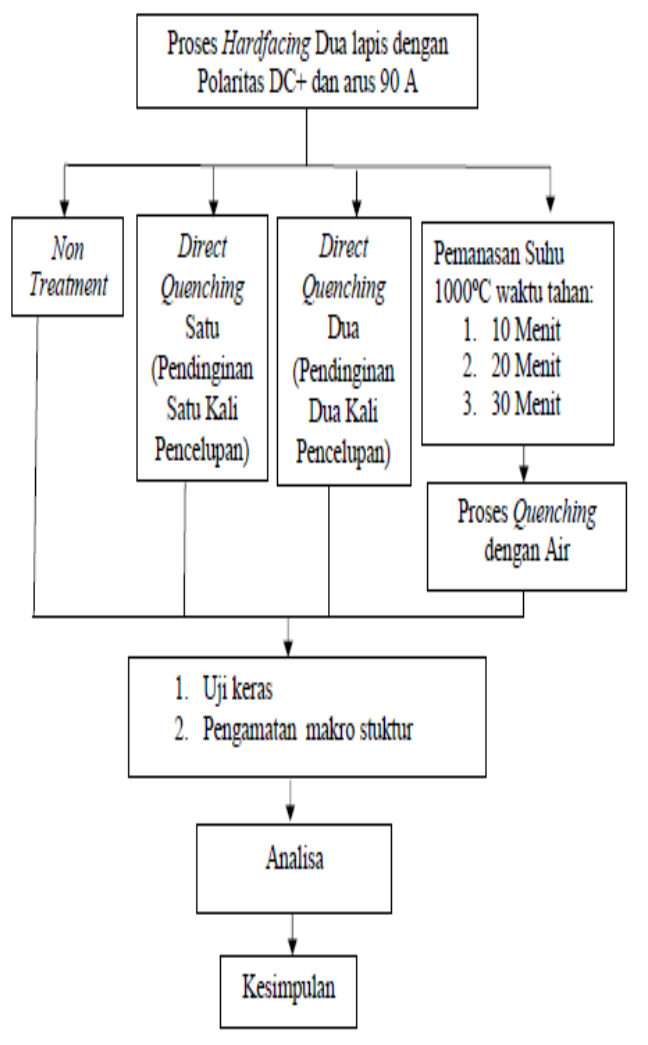

Gambar 1 Diagram Alir Penelitian

Sebelum proses hardfacing elektroda HV 600 dipanaskan dalam oven elektroda (lihat gambar 2). Pemanasan dilakukan dalam oven dengan suhu $150^{\circ} \mathrm{C}$ selama 1 jam.
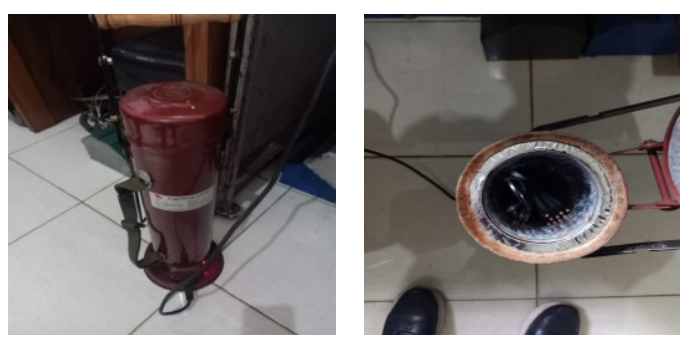

Gambar 2 Oven Elektroda

Proses hardfacing dilakukan dengan menggunakan arus 90A dan polaritas DC+ mesin las SMAW (lihat gambar 3). Proses hardfacing dengan sudut elektroda $90^{\circ}$ dengan teknik mengelas ditarik menggunakan posisi $1 \mathrm{G}$ pelat.

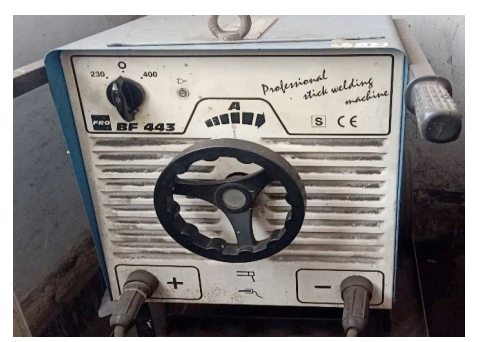

Gambar 3 Mesin Las
Untuk spesimen non treatment (NT) dilakukan hardfacing sebanyak dua lapis. Spesimen direct quenching satu (DQ1) dilakukan hardfacing dua lapis kemudian langsung dicelupkan ke dalam media air. Spesimen direct quenching dua (DQ2) dilakukan hardfacing satu lapis kemudian dicelupkan ke dalam media air dan dihardfacing kembali untuk lapis kedua kemudian dicelupkan kembali ke dalam media air. Hasil perlakuan dapat dilihat pada gambar 4.

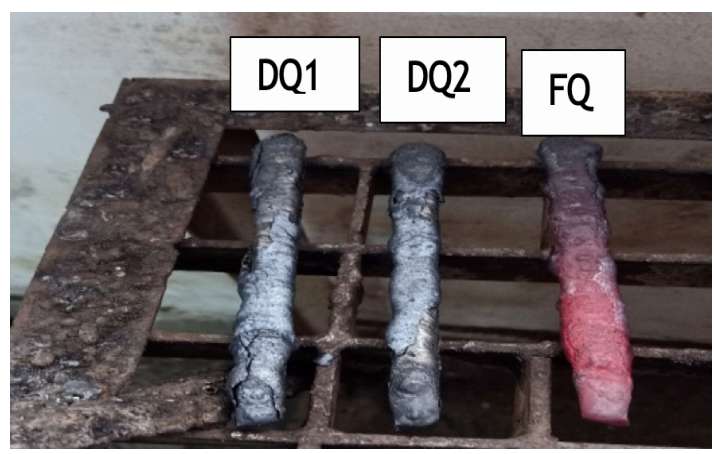

Gambar 4 Spesimen Selesai Hardfacing

Sedangkan untuk spesimen heat treatment dilakukan hardfacing sebanyak dua lapis, kemudian dilakukan heat treatment dalam furnace dengan waktu tahan yang berbeda $(10,20$ dan 30 menit) kemudian di celupkan dalam air. Sebelum dilakukan proses heat tratment, spesimen dipotong menjadi tiga bagian. Untuk spesimen-spesimen ini akan diberikan nama FQ1, FQ2 dan FQ3.

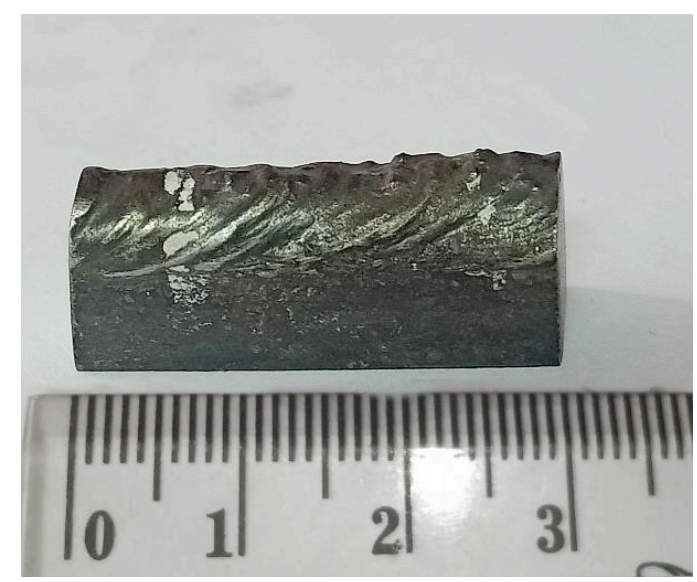

Gambar 5 Hasil Pemotongan Spesimen

Proses heat treatment dilakukan dengan suhu $1000{ }^{\circ} \mathrm{C}$ dengan menggunakan furnace seperti gambar 6 . 


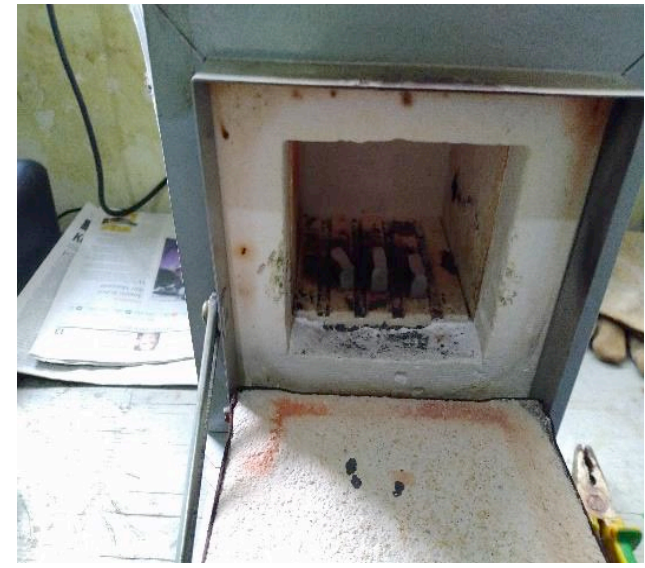

Gambar 6 Proses Heat Treatment

Setelah selesai proses heat treatment dengan variasi holding time, kemudian spesimen di celupkan ke dalam media pendingin air seperti gambar 7 .

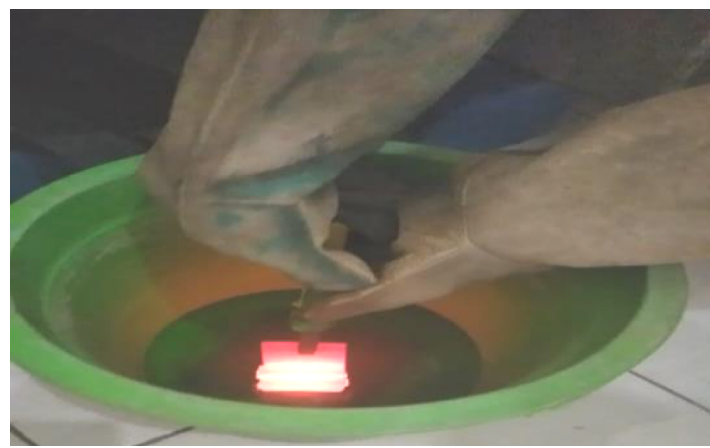

Gambar 7 Proses Quenching Media Air

Setelah spesimen selesai proses heat treatment kemudian spesimen dipotong kembali dan dipoles untuk diuji keras. Pemolesan dilakukan dari amplas yang paling kasar sampai dengan amplas yang lebih halus (120 sd 2000).

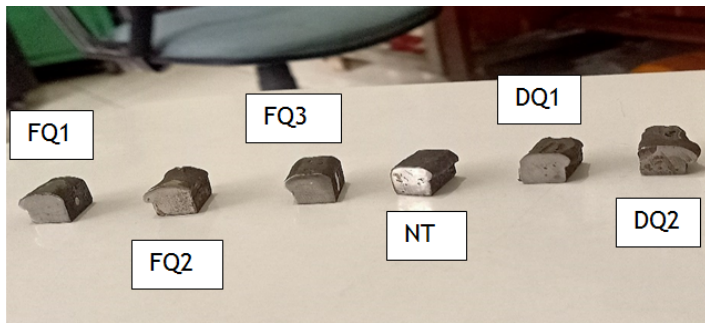

Gambar 8 Spesimen Untuk Uji Keras

Setelah spesimen selesai dilakukan pemolesan kemudian spesimen dilakukan uji keras seperti pada gambar 8. Uji keras menggunakan alat uji keras vickers FV-3000e dengan beban $5 \mathrm{kgf}$. Pengambilan data dilakukan sebanyak tiga titik (pengulangan).

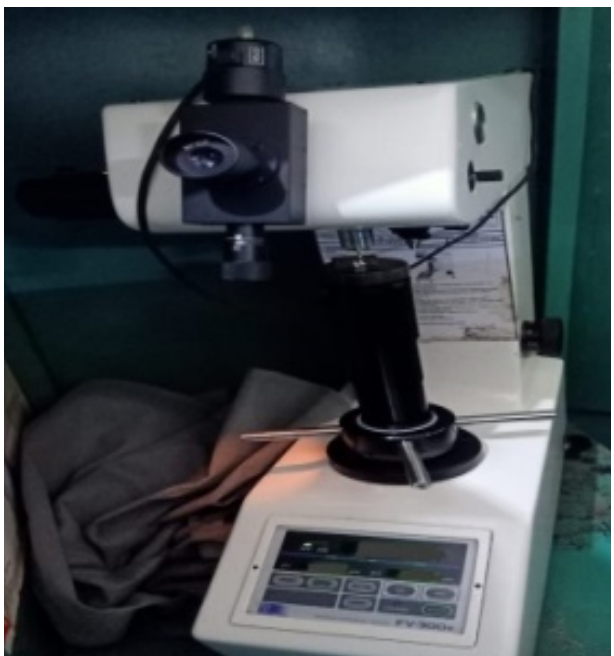

Gambar 9 Uji Keras Vickers

Setelah semua spesimen selesai dilakukan uji kekerasan kemudian dilakukan pemolesan kembali lalu dilakukan pengamatan struktur makro. Spesimen terlebih dahulu dilakukan proses pemolesan dengan amplas 120 sd 2000. Kemudian spesimen dilakukan proses etsa dengan cairan alkohol murni sebanyak $97 \%$ yang dicampur dengan asam nitrat $\left(\mathrm{HNO}_{3}\right)$ sebanyak $3 \%$.

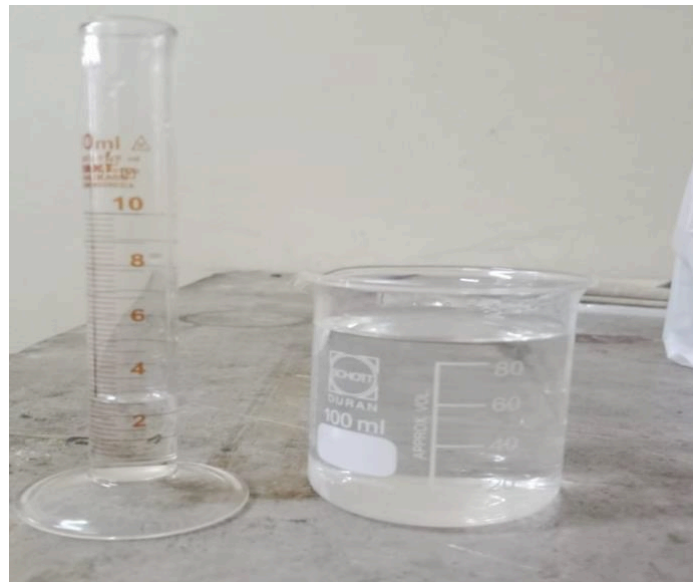

Gambar 10 Larutan etsa

\section{HASIL DAN PEMBAHASAN}

\section{Hasil Uji Keras}

Tabel 1 memperlihatkan hasil dari pengujian kekerasan. Berdasarkan tabel 1 tersebut, dapat diketahui bahwa spesimen direct quenching (DQ) dan furnace quenching (FQ), nilai kekerasan paling tinggi terdapat di spesimen furnace quenching yang dilakukan heat treatment dengan holding time 10 menit dengan nilai kekerasan 716,30 VHN (FQ1). Sedangkan yang paling rendah terdapat spesimen non treatment dengan 
nilai kekerasan 551,93 VHN (NT) untuk lebih jelasnya bisa dilihat dalam gambar 11 .

Tabel 1 Hasil Uji Keras

\begin{tabular}{cccc}
\hline Spesimen & $\begin{array}{c}\text { Titik Uji } \\
\text { keras }\end{array}$ & $\begin{array}{c}\text { Nilai } \\
\text { (VHN) }\end{array}$ & $\begin{array}{c}\text { Rata-Rata } \\
\text { (VHN) }\end{array}$ \\
\hline \multirow{2}{*}{ DQ1 } & 1 & 604,9 & \\
& 2 & 587,2 & 581,93 \\
& 3 & 553,7 & \\
\hline \multirow{2}{*}{ DQ2 } & 1 & 639 & \\
& 2 & 633,8 & 635,33 \\
& 3 & 633,2 & \\
FQ1 & 1 & 705,3 & \\
& 2 & 709,7 & 716,3 \\
& 3 & 733,9 & \\
FQ2 & 1 & 644,9 & \\
& 2 & 646,6 & 640,53 \\
& 3 & 630,1 & \\
FQ3 & 1 & 595,3 & \\
& 2 & 603,9 & 599,77 \\
& 3 & 600,1 & \\
\multirow{2}{*}{ NT } & 1 & 538,6 & \\
& 2 & 575,3 & 551,93 \\
& 3 & 541,9 & \\
\hline
\end{tabular}

Tingkat kekerasan dari suatu material akan lebih tinggi setelah dilakukannya quenching. Pada gambar 11 dapat diketahui pada spesimen $D Q$ nilai kekerasan yang paling tinggi adalah pada spesimen yang dilakukan direct quenching dua kali (DQ2) yaitu 635,33 VHN, sedangkan pada spesimen yang dilakukan direct quenching satu kali (DQ1) nilai kekerasanya 581,93 VHN.

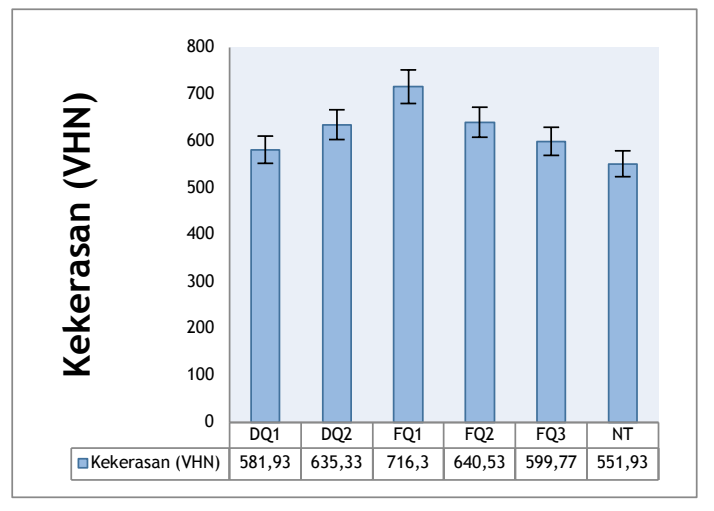

Gambar 11 Diagram Hasil Uji Keras

Kekerasan direct quenching masih lebih rendah jika dibandingkan dengan spesimen furnace quenching, hal ini disebabkan karena proses pengelasan yang mengakibatkan logam induk dan pengisi mencair hanya membutuhkan waktu yang sangat singkat dan temperatur yang lebih tinggi yaitu sekitar $1500^{\circ} \mathrm{C}$ (Ikhtisholiyah, 2017). Proses yang sangat singkat tersebut (sekitar 2 menit) tidak cukup waktu untuk difusi karbon, sehingga kekerasannya lebih rendah jika dibandingkan dengan furnace quenching (Utama et al. 2016). Minimal waktu 5 menit diperlukan guna mengeraskan baja karbon rendah (Dalil et al., 1999).

Pada spesimen furnace quenching nilai kekerasan yang paling tinggi adalah spesimen yang dilakukan heat treatment dengan holding time 10 menit dengan nilai kekerasan $716,30 \mathrm{VHN}$, hal ini mungkin dikarenakan terbentuk distribusi martensit lebih banyak ditemukan pada sampel tersebut (Hidayat et al., 2017). Selain dari itu kemungkinan banyak karbida terbentuk dengan ukuran kristal (crystallite size) yang besar (Kurniawan dan Setiyorini, 2014). Sedangkan nilai kekerasan yang paling rendah terdapat pada spesimen non treatment dengan nilai kekerasan 551,93 VHN. Pada hasil uji keras spesimen furnace quenching semakin lama pada saat di heat treatment akan semakin rendah nilai kekerasannya, hal ini mungkin disebabkan karena ukuran butir (grain size) yang semakin membesar ketika semakin lama dilakukan holding time (Utama et al. 2016). Selain dari itu kemungkinan struktur mikro yang terbentuk adalah full austenite dengan sedikit karbida yang terbentuk pada matriks austenite (Kurniawan dan Setiyorini, 2014).

Hal ini tidak sebanding dengan penelitan yang dilakukan oleh Susetyo dkk (Susetyo et al. 2020) yang mengemukakan semakin lama pada saat di heat treatment akan semakin tinggi nilai kekerasannya mungkin disebabkan oleh media pendingin berbeda yang digunakan dan holding time yang terlalu lama. Menurut Dalid dkk (Dalil et al., 1999), baja karbon rendah hanya perlu holding time 5 menit sampai 15 menit dianggap sudah memadai.

\section{Hasil Foto Struktur Makro}

Pada proses foto makro ini bertujuan untuk mengetahui daerah batasan yang terdiri dari daerah weld metal, dan daerah base metal pada hardfacing material di masing-masing spesimen.

Pada gambar 12 dapat terlihat antara weld metal (WM) dan base metal (BM). Dapat diketahui hasil foto strukur makro tidak terdapat adanya cacat pengelasan baik pada WM maupun BM, sehingga bisa dikatakan bahwa hasil lasan dapat diterima.

Dari gambar 12 juga dapat terlihat bahwa penetrasi las ke dalam base metal dapat teraglomerasi dengan baik. Seperti diketahui pengelasan dengan polaritas DC+ akan menghasilkan penetrasi dangkal dan menghasilkan kekerasan yang tinggi jika 
dibandingkan dengan polaritas yang lain, karena heat input pada elektroda adalah $70 \%$ dan pada base mental adalah 30\%. Sehingga lapisan keras yang terbentuk dapat melindungi base metal dari benturan.

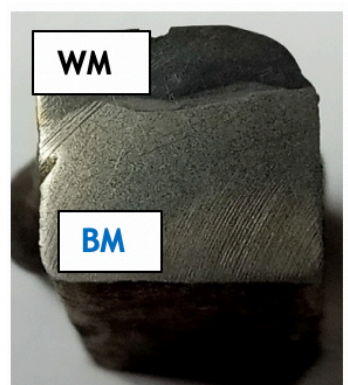

(a)

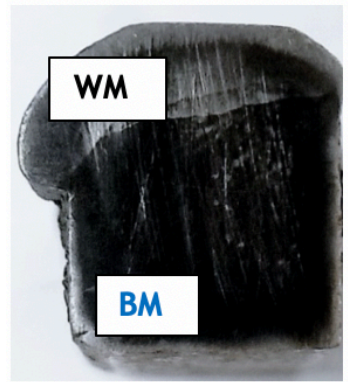

(c)

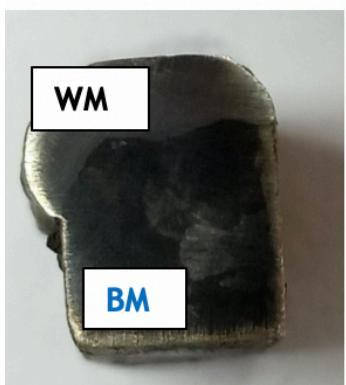

(e)

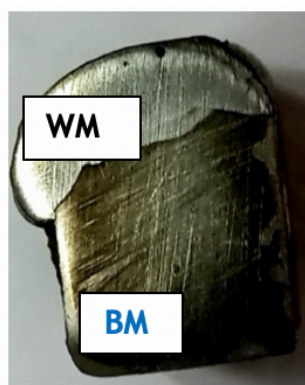

(b)

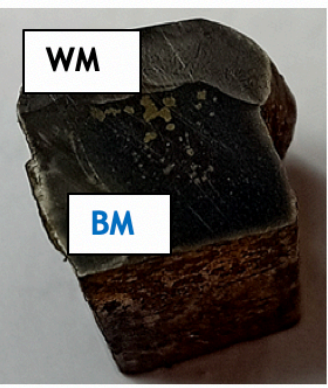

(d)

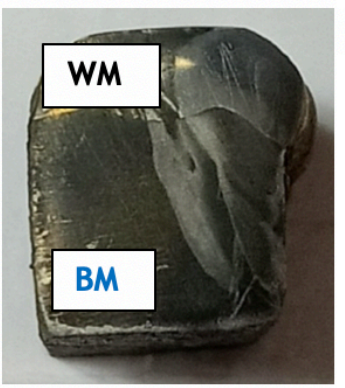

(f)
Gambar 12 Foto Struktur Makro; (a) NT; (b) DQ1; (c) DQ2; (d) FQ1; (e) FQ2; (f) FQ3

\section{SIMPULAN}

Berdasarkan hasil hardfacing 2 lapis pada baja karbon rendah menggunakan elektroda HV 600 yang di heat treatment temperatur $1000^{\circ} \mathrm{C}$ dengan variasi holding time serta dilakukan quenching menggunakan air dapat disimpulkan, bahwa pada spesimen direct quenching mempengaruhi nilai kekerasan, pada spesimen DQ2 lebih tinggi dibandingkan dengan DQ1, dimana pada spesimen DQ1 nilai kekerasannya 581,93 VHN, dan pada spesimen DQ2 nilai kekerasannya 635,33 VHN.
Pada spesimen furnace quenching mempengaruhi nilai kekerasan, Semakin lama holding time pada saat heat treatment maka nilai kekerasan semakin menurun. Dimana nilai kekerasan paling tinggi terdapat di spesimen holding time 10 menit dengan nilai kekerasan 716,3 VHN, dan nilai kekerasan paling rendah terdapat dispesimen holding time 30 menit dengan nilai kekerasan 599,77 VHN. Fenomena ini disebabkan oleh pembentukan karbida dan ukuran kristal yang bervariasi.

Furnace quenching maupun direct quenching menghasilkan kekerasan yang lebih tinggi jika dibandingkan dengan non treatment. Penggunaan direct quenching sangat menjanjikan, karena dapat meningkatkan nilai kekerasan tanpa mengeluarkan biaya untuk pemanasan ulang dalam tungku (furnace heat treatment).

\section{UCAPAN TERIMA KASIH}

Terima kasih kepada Laboratorium produksi, Las dan Material, Teknik Mesin Universitas Negeri Jakarta yang telah banyak memfasilitasi dalam penyelesaian riset ini.

\section{DAFTAR PUSTAKA}

Ahmed, S.R., Agarwal, L.A. and Daniel, B.S.S., 2015. Effect of different post weld heat treatments on the mechanical properties of $\mathrm{Cr}$-Mo boiler steel welded with SMAW process. Materials Today: Proceedings, 2(4-5), pp.1059-1066.

Bangsawan, I.G., 2012. Pengaruh Variasi Temperatur Dan Holding Time Dengan Media Quenching Oli Mesran Sae 40 Terhadap Struktur Mikro Dan Kekerasan Baja Assab 760. Jurnal Nosel, 1(2).

Basori, B. and Syamsuir, S., 2019. Pengaruh Arus Terhadap Struktur Mikro Dan Kekerasan Lasan JIS Z 3251 DF2A-350-R. Jurnal Kajian Teknik Mesin, 4(1), pp.2125.

Dalil, M., Adhy, P. and Ismet, I., 1999. Pengaruh Perbedaan Waktu Penahanan Suhu Stabil (Holding Time) Terhadap Kekerasan Logam. Jurnal Natur Indonesia II, 1, pp.12-17.

Hafni, H., 2015. Pengaruh Waktu Tahan Proses Pack Carburizing Pada Baja Karbon Rendah Dengan Menggunakan Calcium Carbonat Dan Arang Tempurung Kelapa, Di Tinjau Dari Kekerasan. Jurnal Teknik Mesin (JTM), 5(2).

Hidayat, T., Hartono, P. and Sujatmiko, S., 2017. Analisa Pengaruh Suhu Pada Media 
Pendingin Terhadap Sifat Mekanis (Kekerasan) Baja S45C Pada Proses Hardening. Jurnal Teknik Mesin, 6(02).

Ikhtisholiyah, I., 2017. Optimasi Besarnya Suhu pada Ladle untuk Baja Low Carbon dengan Metode Fuzzy-Mamdani (Studi Kasus PT. Ispatindo). Zeta-Math Journal, 3(2), pp.41-45

Kurniawan, B.E. and Setiyorini, Y., 2014. Pengaruh variasi Holding Time Pada Perlakuan Panas Quench Annealing Terhadap Sifat mekanik dan Mikro Struktur Pada Baja mangan AISI 3401. Jurnal Teknik ITS, 3(1), pp.F113F16.

Oo, H.Z. and Muangjunburee, P., 2018. Wear behaviour of hardfacing on $3.5 \%$ chromium cast steel by submerged arc welding. Materials Proceedings, 5(3), pp.9281-9289.

Saini, S., Sahni, G. \& Singh, B., 2016, A Review On Hardfacing And Wear Reducing Techniques On Industrial Valves. International Journal of Research in Engineering \& Technology, 4(8), 23-28.

Sardi, V.B., Jokosisworo, S. and Yudo, H., 2018. Pengaruh Normalizing dengan Variasi Waktu Penahanan Panas (Holding Time) Baja ST 46 terhadap Uji Kekerasan, Uji Tarik, dan Uji Mikrografi. Jurnal Teknik Perkapalan, 6(1), 142-149.

Singh, H., 2014. Studies the Effect of Iron Based Hardfacing Electrodes on Stainless Steel Properties Using Shielded Metal Arc Welding Process. International Journal of Research in Advent Technology, 2(4).

Soebagyo, H. and Kusuma, G.C., 2019. Pemeriksaan Sambungan Las Aluminium Pada Struktur Kereta Api Ringan Dengan Metode Non-Destructive Test. Jurnal ASIIMETRIK: Jurnal IImiah Rekayasa \& Inovasi, 1(1), pp.58-64.

Sopiyan, Syamsuir \& Nofendri, Y., 2019, 'Evaluasi Hasil Hardfacing Elektroda HV 350 Pasca Quenching Media Air, Coolant dan Oli', Jurnal Kajian Teknik Mesin, 4(2), 104-107.

Susetyo, F.B., Dwiyati, S.T. and Hutomo, M.B.P., 2020. Fabrikasi Lapisan Pada Baja 0,192\% C Sebagai Alternatif Pahat Bubut. JURNAL KAJIAN TEKNIK MESIN, 5(1), pp.42-47.

Susetyo, F.B., Kholil, A. and Fatihuddin, M., 2019. Efek Polaritas Dan Media Pendingin Terhadap Nilai Kekerasan
Permukaan Hardfacing Baja Karbon Rendah. Jurnal Konversi Energi dan Manufaktur UNJ, 6(1), pp.1-5.

Utama, A.R.S., Wahab, A. and Robbi, N., 2017. Pengaruh Temperatur Dan Holding Time Dengan Pendingin Yamacoolant Terhadap Baja ASSAB 760. Jurnal Teknik Mesin, 6(01). 